Research Article

\title{
A NOVEL HETEROGENEOUS MODEL OF LAYERED STRUCTURES FOR NUMERICAL MODELING AND SIMULATION AT MICROWAVE FREQUENCIES VIA FDTD
}

\section{Ummu SAHIN SENER ${ }^{1^{*}}$ and Sebahattin EKER ${ }^{2}$}

\begin{abstract}
Numerous destructive and nondestructive techniques using different energy sources have been offered for material characterization. Among the nondestructive testing techniques that suggest monitoring the content of different materials and concrete structures, the techniques using microwaves offer important advantages because they are not radioactive, provide good penetration, provide excellent contrast with rebar and are not affected by ambient temperature. In this paper, a non-destructive testing (NDT) technique is represented to simulate a novel heterogeneous rectangular geometric structures containing different materials such as concrete, pavement, mortar, rebar and soil based on their dielectric properties. Maxwell wave equations are used to simulate how wave propagates in structures with different dielectric properties. For numerical simulation a Finite Difference Time Domain (FDTD) is used and Absorbing Boundary Conditions (ABCs) is proposed to prevent re-entering of propagating waves into the computation domain.
\end{abstract}

Key words: FDTD, layered media, microwave, nondestructive testing, wave equation.

\section{Introduction}

Examination, strengthening and repairing the strength of infrastructures such as roads and bridges is an important issue for public safety and effective infrastructure management [1]. Nondestructive inspection techniques are more advantageous than other inspection techniques since they do not destroy the integrity of the examined structure [2-5]. There are many noninvasive techniques to detect layers, delamination and defects in the structures, such as acoustic, thermal, radiographic, microwave and radar methods. Thanks to using the electromagnetic (EM) waves in examination of the structures, natural materials such as soil and rocks, as well as artificial materials such as concrete and asphalt can be imaged, in addition, it is one of the most powerful methods used for the detection and identification of metallic or non-metallic objects buried in mediums (concrete, mortar, asphalt, soil, rock, pavement) [6,7]. When it is desired to non-destructively examine any construction via EM waves it is seen that materials with electrically different properties are present together [8-11].

Ground Penetrating Radar (GPR) is an important geophysical tool for underground imaging, based on the analysis of the propagation and reflection of EM waves at microwave frequencies [1214]. The different GPR models based on the same operation principle, the transmitting antenna is

\footnotetext{
1 Department of Mathematical Engineering University of Yildiz Technical University, Istanbul, Turkey, (ummusahin@klu.edu.tr) https://orcid.org/0000-0001-9055-8734

2 Informatics Institute University of Istanbul Technical University, Istanbul, Turkey, (ekerseb@itu.edu.tr) (iDhttps://orcid.org/00000002-0259-3781
} 
located directly above the surface and propagates the short pulse through the ground. It has been demonstrated how successful GPR technique is in rigid and flexible pavements, placing dowels, detecting voids or loss of support under the boards or detecting any and cracks [15,16]. GPR, which is used for overlay thickness estimation, has become one of the most used methods because of its nondestructive inspection, rapid results, cost-effectiveness and enabling it to be done more efficiently without breaking the pavement structure or highway road. When we want to examine an environment nondestructively using GPR that based on the microwave propagation technique it is difficult to predict what environment to encounter [17-20]. Precisely for this reason, numerical pre-modeling of the environments to be examined using GPR both reduces cost and prevents loss of time [21]. Numerical modeling of the propagation of the electromagnetic field in heterogeneous environments enables us to have information about the environments where interpretation of (GPR) data, investigating the causes of reflections and diffractions in GPR maps, analyzing radargrams analysis and analyzing wave propagation analytically where analytic analysis of wave propagation is not possible [22].

The differences in the material properties of the four structural components (concrete, mortar, pavement, rebar) create challenging problems in predicting the behavior of the integrated structural system since concrete is a heterogeneous structure consisting of water, cement, sand, coarse aggregate and air in addition, the heterogeneous structure called mortar consists of water, cement, sand and air $[23,24]$. Simple models, taken as cross-sections of large structures, can provide information about the behavior of a system that is lost in the details of more complex models and situations. Materials with many different dielectric properties have been successfully modeled in the same geometric structure. Therefore, the purpose of this study is to explain how the wave in microwave frequencies emitted from three different point sources, in a layered environment composed of materials with different dielectric properties and rebar. The response of layered media including pavement, concrete and soil is investigated by numerical simulation. In the following section, Maxwell's curl equations and FDTD methods with PML boundary conditions are ensured $[25,26]$. The geometrical configuration of the 2D layered structures described and propagation of the electromagnetic waves in layered media is investigated numerically [27].

\section{Theoretical Framework and Simulation Experiments}

Numerical calculation methods are preferred to solve complex electromagnetic (EM) problems, which are difficult or impossible to solve analytically. Since the incident wave encounters air/concrete/pavement interface reflection, only part of the energy is transmitted to the concrete or pavement and interacts with the media interfaces, delamination, rebar and defects. FDTD is a method, which provides convergence to Maxwell's differential equations in time period by dividing the calculation region into stepwise rectangular elements. Since Maxwell divergence equations are already provided by the developed FDTD updating equations, only Maxwell's curl equations are needed while deriving the FDTD algorithm [7]. Maxwell curl equations in Cartesian coordinates for the linear, isotropic, nondispersive and lossy medium is presented below:

$$
\begin{gathered}
\nabla \times \mathbf{H}=\varepsilon \frac{\partial \mathbf{E}}{\partial t}-\sigma^{e} \mathbf{E}-\mathbf{J}_{i} \\
\nabla \times \mathbf{E}=-\mu \frac{\partial \mathbf{H}}{\partial t}-\sigma^{m} \mathbf{H}-\mathbf{M}_{i}
\end{gathered}
$$


When components of (1) and (2) are reformulated two decoupled groups of equations are obtained. These two groups are TE waves, which contain Ex, Ey and Hz components and TM waves, which contains $\mathrm{H}_{\mathrm{x}}, \mathrm{H}_{\mathrm{y}}$ and $\mathrm{E}_{\mathrm{z}}$ components. In Cartesian coordinate system $\mathrm{TE}$ waves has three components as follows:

$$
\begin{gathered}
\frac{\partial E_{x}}{\partial t}=\frac{1}{\varepsilon_{x}}\left(\frac{\partial H_{z}}{\partial y}-\sigma_{x}^{e} E_{x}-J_{i x}\right) \\
\frac{\partial E_{y}}{\partial t}=\frac{1}{\varepsilon_{y}}\left(\frac{\partial H_{z}}{\partial x}-\sigma_{y}^{e} E_{y}-J_{i y}\right) \\
\frac{\partial H_{z}}{\partial t}=\frac{1}{\mu_{z}}\left(\frac{\partial E_{x}}{\partial y}-\frac{\partial E_{y}}{\partial x}-\sigma_{z}^{m} H_{z}-M_{i z}\right)
\end{gathered}
$$

These equations can be represented in discrete form both space and time domains, electric and magnetic fields are computed at each grid cell iteratively and separately based on the Yee's algorithm by courtesy of the FDTD method [25,27]. First and second central differences are applied to approximate the differential forms of Maxwell's equations. As a result, the equations for TE mode that will be used in the 2D simulations are obtained as follows:

$$
\begin{aligned}
E_{x}^{n+1}(i, j) & =C_{e x e}(i, j) \times E_{x}^{n}(i, j)+C_{e x h z}(i, j) \times\left(H_{z}^{n+\frac{1}{2}}(i, j)-H_{z}^{n+\frac{1}{2}}(i, j-1)\right) \\
& +C_{e x j}(i, j) \times J_{i x}^{n+\frac{1}{2}}(i, j)
\end{aligned}
$$

where

$$
\begin{gathered}
C_{e x e}(i, j)=\frac{2 \varepsilon_{x}(i, j)-\Delta t \sigma_{x}^{e}(i, j)}{2 \varepsilon_{x}(i, j)+\Delta t \sigma_{x}^{e}(i, j)}, \\
C_{e x h z}(i, j)=\frac{2 \Delta t}{\left(2 \varepsilon_{x}(i, j)+\Delta t \sigma_{x}^{e}(i, j)\right) \Delta y}, \\
C_{e x j}(i, j)=\frac{2 \Delta t}{2 \varepsilon_{x}(i, j)+\Delta t \sigma_{x}^{e}(i, j)} . \\
E_{y}^{n+1}(i, j)=C_{e y e}(i, j) \times E_{y}^{n}(i, j)+C_{e y h z}(i, j) \times\left(H_{z}^{n+\frac{1}{2}}(i, j)-H_{z}^{n+\frac{1}{2}}(i-1, j)\right) \\
+C_{e y j}(i, j) \times J_{i y}^{n+\frac{1}{2}}(i, j)
\end{gathered}
$$

where

$$
\begin{aligned}
& C_{\text {eye }}(i, j)=\frac{2 \varepsilon_{y}(i, j)-\Delta t \sigma_{y}^{e}(i, j)}{2 \varepsilon_{y}(i, j)+\Delta t \sigma_{y}^{e}(i, j)}, \\
& C_{e y h z}(i, j)=\frac{2 \Delta t}{\left(2 \varepsilon_{y}(i, j)+\Delta t \sigma_{y}^{e}(i, j)\right) \Delta x}, \\
& C_{e y j}(i, j)=\frac{2 \Delta t}{2 \varepsilon_{y}(i, j)+\Delta t \sigma_{y}^{e}(i, j)} .
\end{aligned}
$$




$$
\begin{aligned}
H_{z}^{n+\frac{1}{2}}(i, j) & =C_{h z h}(i, j) \times H_{z}^{n-\frac{1}{2}}(i, j)+C_{h z e x}(i, j) \times\left(E_{x}^{n}(i, j+1)-E_{x}^{n}(i, j)\right) \\
& +C_{h z e y}(i, j) \times\left(E_{y}^{n}(i+1, j)-E_{y}^{n}(i, j)\right)+C_{h z m}(i, j) \times M_{i z}(i, j),
\end{aligned}
$$

where

$$
\begin{aligned}
& C_{h z h}(i, j)=\frac{2 \mu_{z}(i, j)-\Delta t \sigma_{z}^{m}(i, j)}{2 \mu_{z}(i, j)+\Delta t \sigma_{z}^{m}(i, j)}, \\
& C_{\text {hzex }}(i, j)=\frac{2 \Delta t}{\left(2 \mu_{z}(i, j)+\Delta t \sigma_{z}^{m}(i, j)\right) \Delta y}, \\
& C_{h z e y}(i, j)=-\frac{2 \Delta t}{\left(2 \mu_{z}(i, j)+\Delta t \sigma_{z}^{m}(i, j)\right) \Delta x}, \\
& C_{h z m}(i, j)=-\frac{2 \Delta t}{2 \mu_{z}(i, j)+\Delta t \sigma_{z}^{m}(i, j)} .
\end{aligned}
$$

To solve the open geometry problems with FDTD, an absorbing boundary condition (ABC) is required to permit the EM waves passing out of the problem space without distorting the fields or reflecting into the computation domain [26]. The two-dimensional computational domain is divided into cells of much smaller size than the wavelength. Four different simulation setup are introduced and the entire computational domain is a rectangular region of $0.5 \times 0.25 \mathrm{~m}$. The numerical domain is obtained by dividing into 200 grids in the $x$-axis and 100 grids in the $z$-axis, $\Delta x=\Delta z=0.0025 \mathrm{~m}$ and $\Delta x=\Delta z \cong \lambda / 120$.

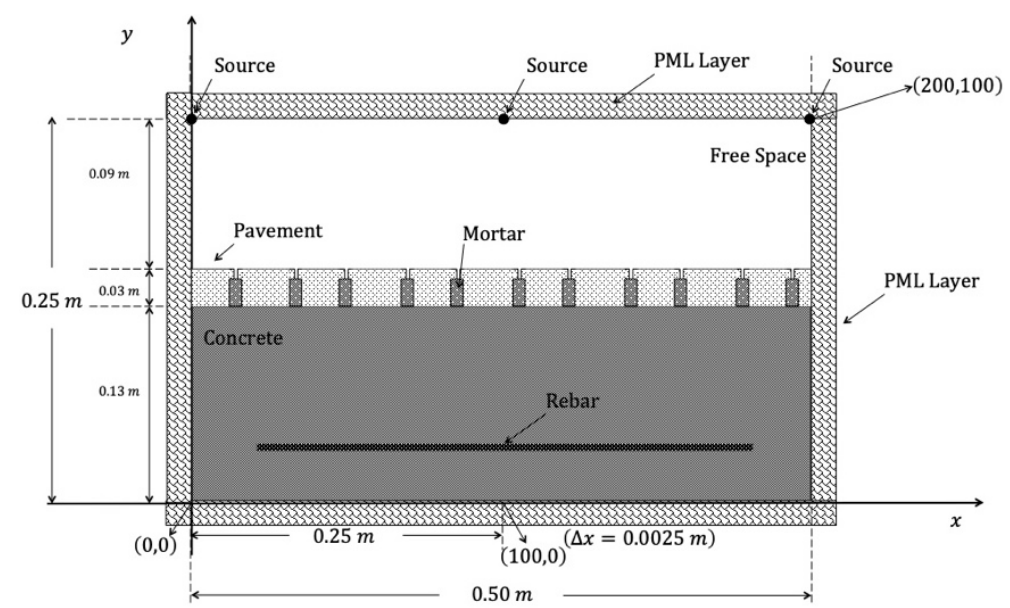

Figure 1. Case A: Layered media with pavement, mortar, concrete and horizontal rebar

In the first numerical experiment namely Case A in Fig. 1, a two-layered rectangular specimen with pavement that contain mortar between and concrete including horizontal rebar is used to test the method. The thickness of the concrete is $0.13 \mathrm{~m}$, the height of the pavement $0.03 \mathrm{~m}$, the height of the mortar $0.02 \mathrm{~m}$ and extend of the free space in the y-axis is $0.09 \mathrm{~m}$. The length of the rebar is $0.4 \mathrm{~m}$. 


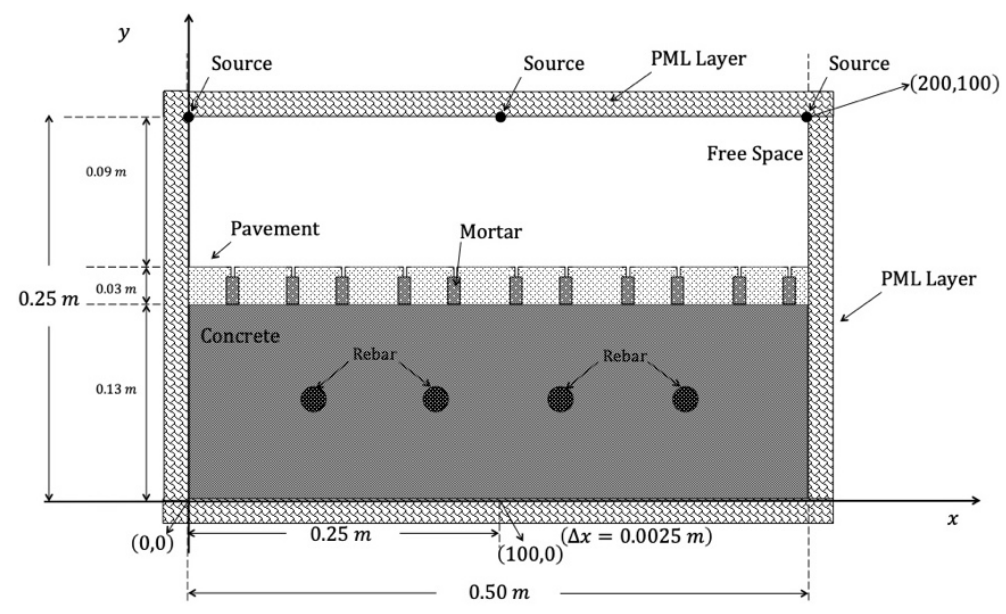

Figure 2. Case B: Layered media with pavement, mortar, concrete and vertical rebar

In Fig. 2 physical model for Case B is introduced, the characteristics of this physical model are the same as the Case A except for the location of the rebar. The diameter of each rebar is $0.015 \mathrm{~m}$, distance between rebar and $x$-axis is equal and $0.05 \mathrm{~m}$. The distances of the centers of the rebar to each other and to the calculation edge are equal and $0.1 \mathrm{~m}$.

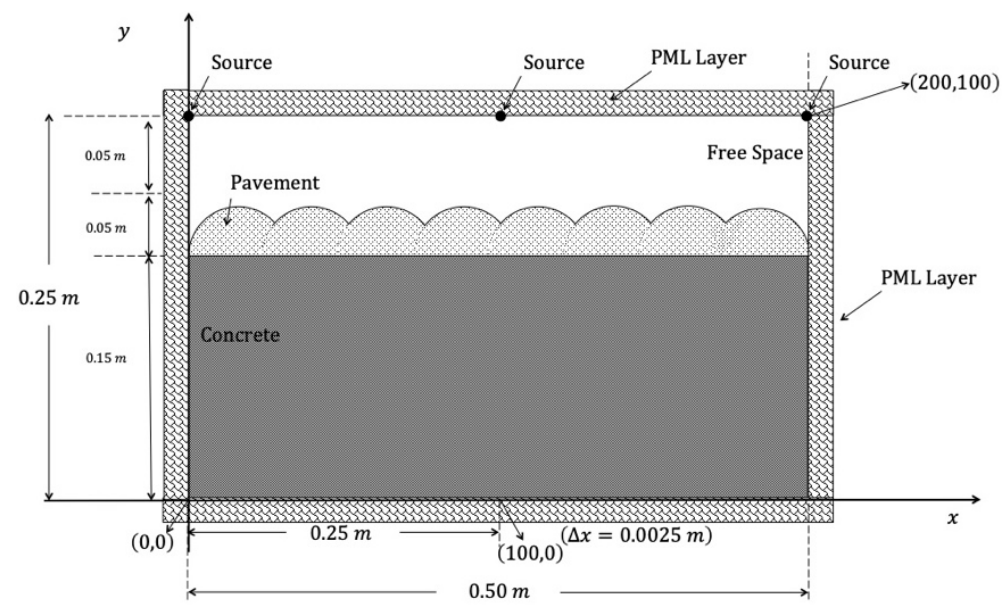

Figure 3. Case C: Layered media with circular pavement and concrete

In Fig. 3 the third simulation setup briefly Case $\mathrm{C}$ is introduced. This model contains circular pavement on concrete layer, the thickness of the concrete is $0.15 \mathrm{~m}$, the distance between maximum point of the pavement and interface of the concrete-pavement is $0.05 \mathrm{~m}$.

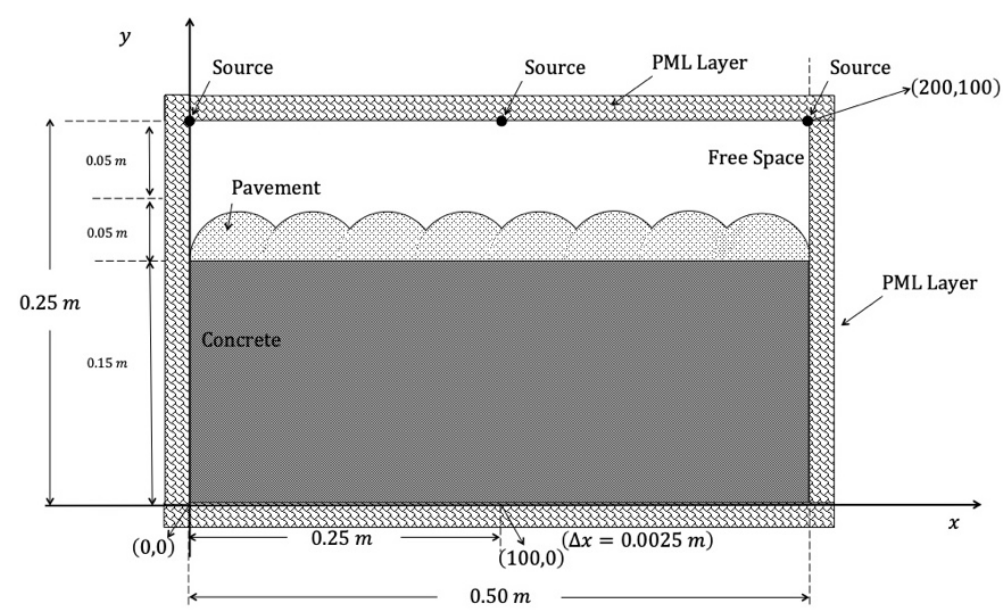

Figure 4. Case D: Layered media with concrete and soil 
In Fig. 4 the last physical model, Case D is given and this model consists of undulating soil surface under concrete layer. The maximum height of the area formed by soil and concrete is $0.125 \mathrm{~m}$ and the distance between $x$-axis and peak of the soil is $0.075 \mathrm{~m}$.

\section{Discussion and Results}

Since the structures are excited by TE plane wave only $\mathrm{E}_{\mathrm{x}}, \mathrm{E}_{\mathrm{y}}$ and $\mathrm{H}_{\mathrm{z}}$ components are calculated. $1.5 \mathrm{GHz}, 3.0 \mathrm{GHz}$ and $6.0 \mathrm{GHz}$ frequencies, which are the center frequency of the $\mathrm{L}, \mathrm{S}, \mathrm{C}$ bands respectively are used for the simulation. At each simulation the sources are pointwise $\mathrm{H}$ hard sources positioned at three different points in one dimension. The dielectric constants of concrete, pavement, mortar and dry soil are $\varepsilon_{\text {concrete }}=7.2, \varepsilon_{\text {pavement }}=5.0, \varepsilon_{\text {mortar }}=4.0, \varepsilon_{\text {soil }}=5.0$ respectively. The conductivity of concrete, pavement, mortar, soil and rebar are $\sigma_{\text {concrete }}=0.1 \mathrm{~S} / \mathrm{m}, \sigma_{\text {mortar }}=0.1 \mathrm{~S} / \mathrm{m}$, $\sigma_{\text {mortar }}=0.1 \mathrm{~S} / \mathrm{m}, \sigma_{\text {soil }}=0.1 \mathrm{~S} / \mathrm{m}, \sigma_{\text {rebar }}=1 \times 10^{7} \mathrm{~S} / \mathrm{m}$ respectively [1]. Simulation results for Case A, Case B, Case C and Case D care given below respectively.

\subsection{Simulation results for Case A:}

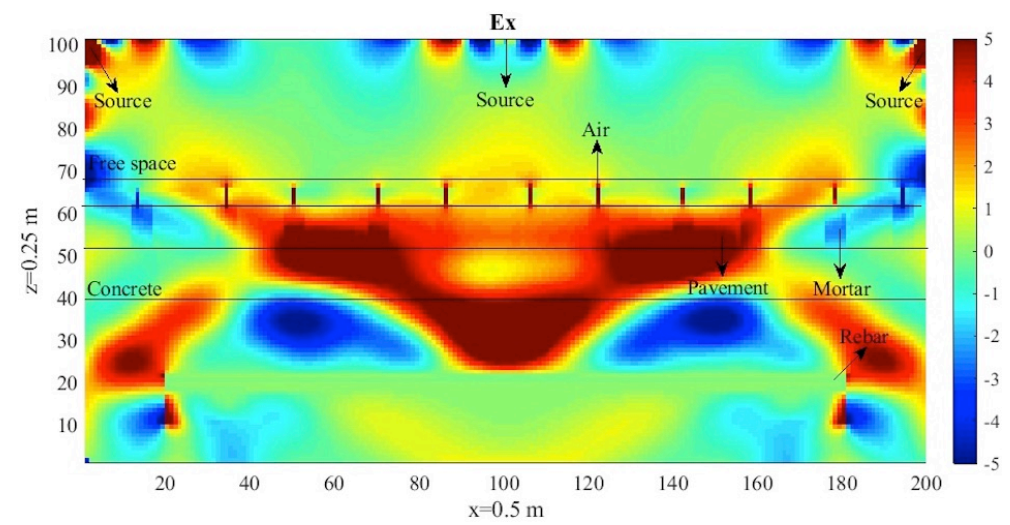

Figure 5. Simulation result for Case $A: E_{x}$ for $1.5 \mathrm{GHz}$ at 500 -time step

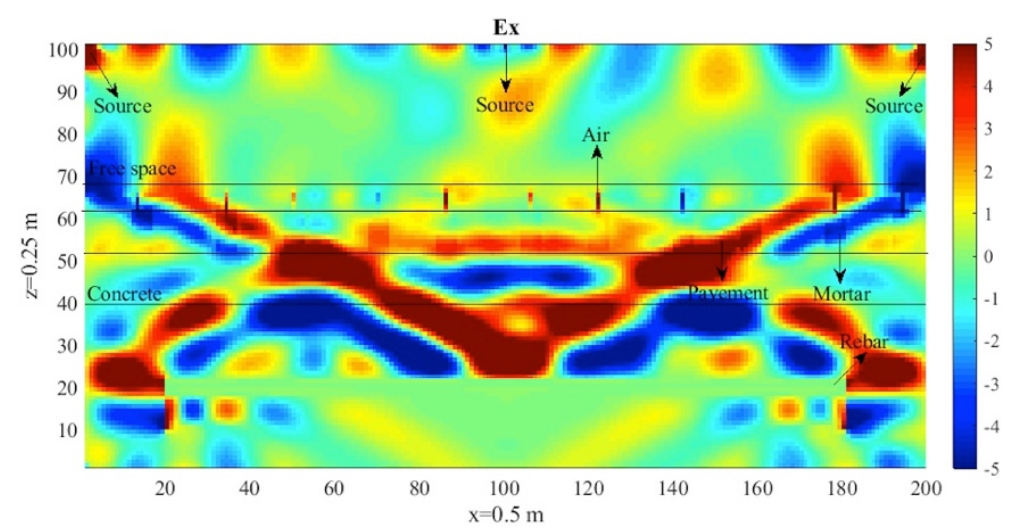

Figure 6. Simulation result for Case $A$ : $\mathbf{E}_{\mathbf{x}}$ for $3.0 \mathrm{GHz}$ at 500 -time step 


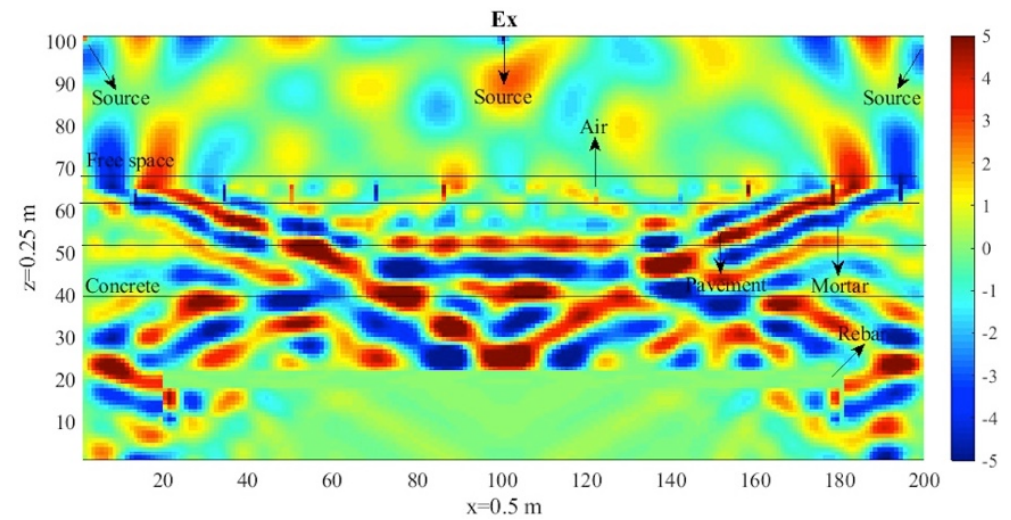

Figure 7. Simulation result for Case $A$ : $E_{x}$ for 3.0 $\mathrm{GHz}$ at 500-time step

In Fig. 5, Fig. 6 and Fig. $7 \mathrm{E}_{\mathrm{x}}$ field distributions at 500-time steps are obtained at $1.5 \mathrm{GHz}, 3.0$ $\mathrm{GHz}$ and $6.0 \mathrm{GHz}$ respectively and these results are related to physical model expressed in Fig.1. In all the figures air gap between pavements can be seen but in Fig. 6 the air gap is clearer. In Fig. 5 mortar layer is more noticeable than the other results and in Fig. 7 horizontal cross-sectional rebar is more distinguishable. In this instance, lower frequencies are more convenient for material characterization and higher frequencies are suitable for rebar detection.

\subsection{Simulation results for Case $B$ :}



Figure 8. Simulation result for Case $B$ : $E_{x}$ for $1.5 \mathrm{GHz}$ at 400 -time step

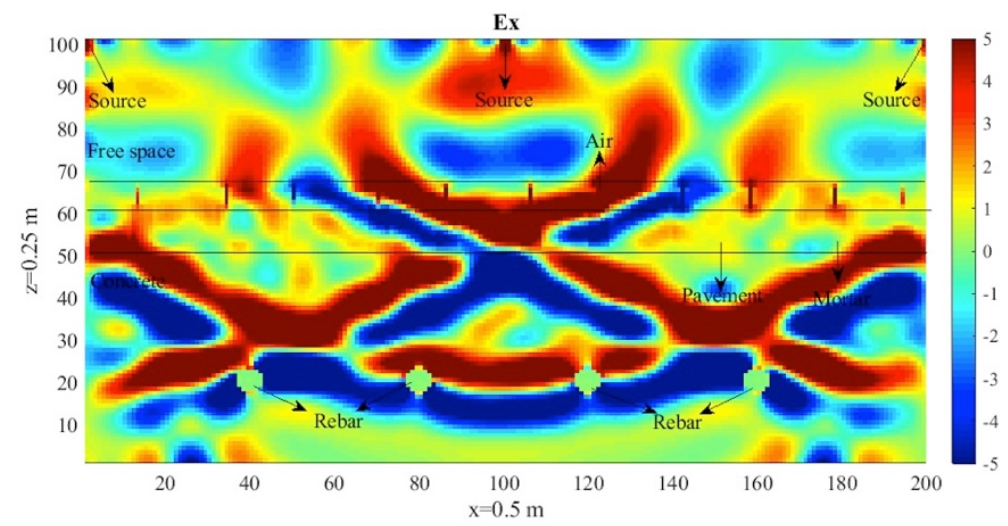

Figure 9. Simulation result for Case $B$ : $E_{x}$ for 3.0 GHz at 400-time step 


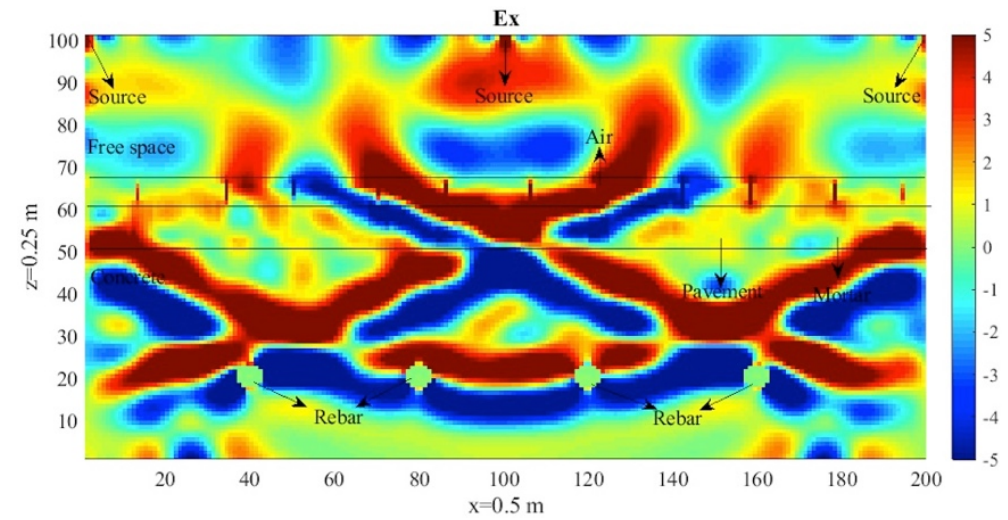

Figure 10. Simulation result for Case $B$ : $E_{x}$ for $6.0 \mathrm{GHz}$ at 400-time step

In Fig. 8, Fig. 9 and Fig. $10 \mathrm{E}_{\mathrm{x}}$ field distributions at 400 time steps are obtained at $1.5 \mathrm{GHz}, 3.0$ $\mathrm{GHz}$ and $6.0 \mathrm{GHz}$ respectively and these results are related to physical model expressed in Fig. 2. Since everything else is the same as the position and number of rebar results for Fig. 1 is similar for Fig. 2. Since in Fig. 2 the electromagnetic wave provides less interaction with the iron in terms of the cross-sectional area less time steps needed. Fig. 9 is the best result for mortar and pavement detection and $6.0 \mathrm{GHz}$ is the most suitable frequency for rebar detection as showed in Fig. 10.

\subsection{Simulation results for Case $\mathrm{C}$ :}



Figure 11. Simulation result for Case $C: E_{x}$ for $1.5 \mathrm{GHz}$ at 250 -time step

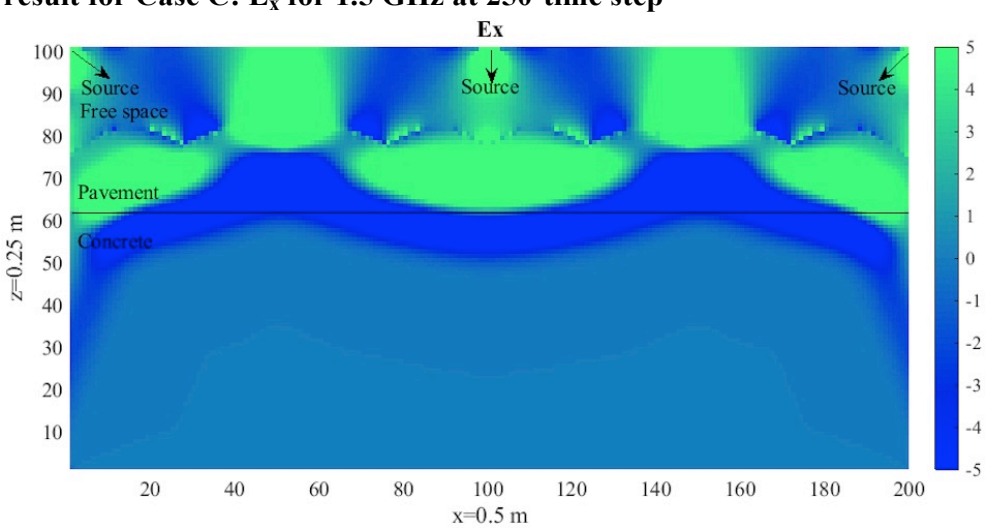

Figure 12. Simulation result for Case $C$ : $E_{x}$ for $3.0 \mathrm{GHz}$ at 250 -time step 


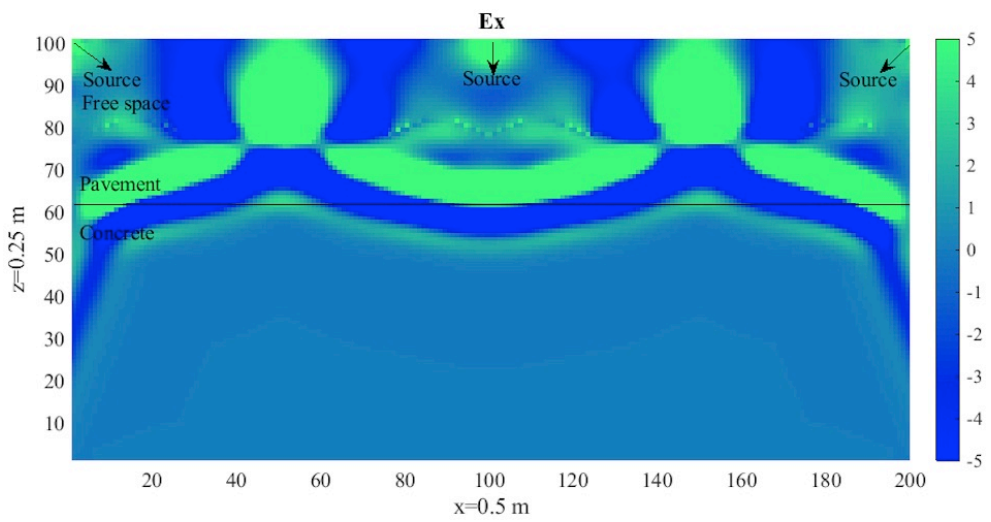

Figure 13. Simulation result for Case $C$ : $E_{x}$ for $6.0 \mathrm{GHz}$ at 250-time step

In Fig. 11, Fig. 12 and Fig. $13 \mathrm{E}_{\mathrm{x}}$ field distributions at 250-time steps are obtained at $1.5 \mathrm{GHz}$, 3.0 GHz and 6.0 GHz respectively and these results are related to physical model expressed in Fig. 3. In this physical model, there is no further layer and rebar under the concrete, so no more time steps are needed. Since lower frequencies are more suitable for material characterization Fig. 11 is the best result for this physical model.

\subsection{Simulation results for Case D:}

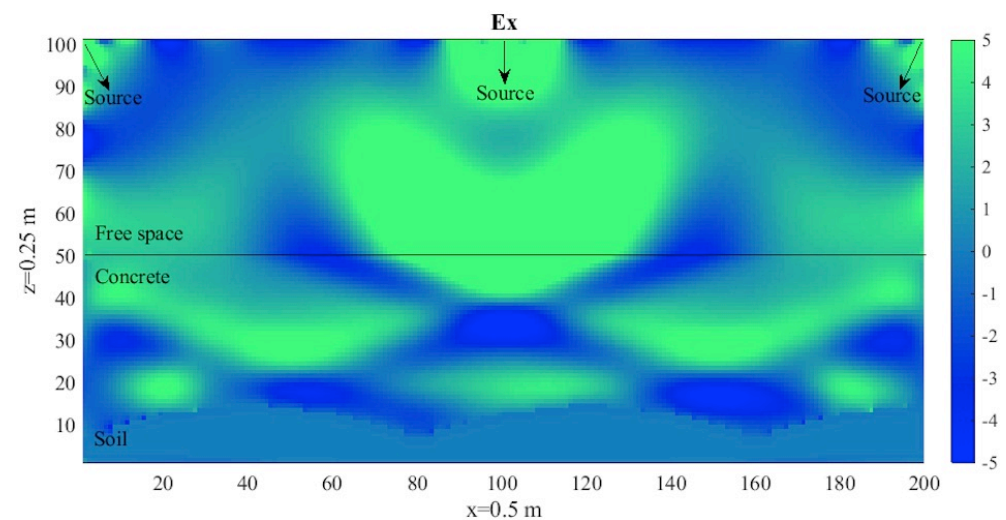

Figure 14. Simulation result for Case $D: E_{x}$ for $1.5 \mathrm{GHz}$ at 400 -time step

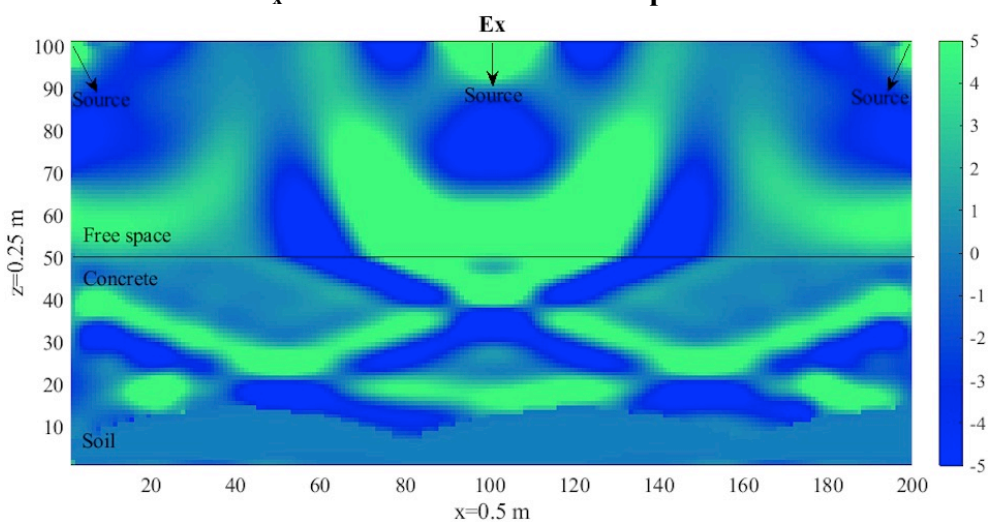

Figure 15. Simulation result for Case $D: E_{x}$ for $3.0 \mathrm{GHz}$ at 400 -time step 


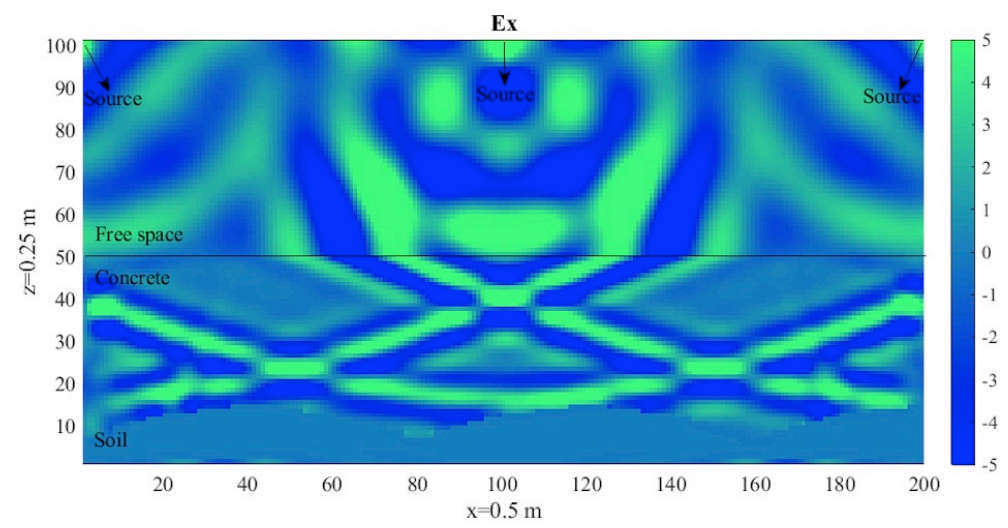

Figure 16. Simulation result for Case $D: E_{x}$ for $6.0 \mathrm{GHz}$ at 400-time step

In Fig. 14, Fig. 15 and Fig. $16 \mathrm{E}_{\mathrm{x}}$ field distributions at 400-time steps are obtained at $1.5 \mathrm{GHz}$, $3.0 \mathrm{GHz}$ and $6.0 \mathrm{GHz}$ respectively and these results are related to physical model expressed in Fig. 4. Since the layered part examined by sending electromagnetic wave is thinner than other physical models, the time step is shorter. In the fourth model, a structure consisting of two different materials is examined. In this model, more time steps are required than the Case $\mathrm{C}$ because the material to be simulated is deeper. As a result, in Fig. 15 and Fig. 16 the soil layer is clearer.

\section{Conclusion}

The layered media may be encountered in bridge, road or different structures are designed as a numerical simulation experiment. The capability of the FDTD method for simulation of layered media containing pavement, mortar concrete rebar and even soil is investigated. The layers of the rectangular structure with pavement, concrete and the rebar inside it are successfully viewed. Since the first and second physical models contain rebar, the rebar can be displayed better at higher frequency in a word at $6.0 \mathrm{GHz}$. Also, different pavement and concrete surfaces are observed in such a way that the thickness of the layers is noticeable, and the best simulation results is obtained at $1.5 \mathrm{GHz}$ and 3.0 $\mathrm{GHz}$ frequencies for microwave radar NDT technique.

\section{References}

[1] Büyüköztürk, O. (1998). Imaging of concrete structures. Ndt and E International, 31(4), 233-243.

[2] Lai, W. W. L., Derobert, X. and Annan, P. (2018). A review of Ground Penetrating Radar application in civil engineering: A 30-year journey from Locating and Testing to Imaging and Diagnosis. Ndt \& E International, 96, 58-78.

[3] Zhao, S., Al-Qadi, I. (2018). Pavement drainage pipe condition assessment by GPR image reconstruction using FDTD modeling. Construction and Building Materials, 154, 1283-1293.

[4] Stryk, J., Matula, R., Pospíšil, K., Dérobert, X., Simonin, J. M. and Alani, A. M. (2017). Comparative measurements of ground penetrating radars used for road and bridge diagnostics in the Czech Republic and France. Construction and Building Materials, 154, 1199-1206.

[5] Fernandes, F. M. and Pais, J. C. (2017). Laboratory observation of cracks in road pavements with GPR. Construction and Building Materials, 154, 1130-1138. 
[6] Tosti, F., Ciampoli, L. B., D'Amico, F., Alani, A. M. and Benedetto, A. (2018). An experimentalbased model for the assessment of the mechanical properties of road pavements using groundpenetrating radar. Construction and Building Materials, 165, 966-974.

[7] Benedetto, A., Tosti, F., Ciampoli, L. B. and D'amico, F. (2017). An overview of groundpenetrating radar signal processing techniques for road inspections. Signal processing, 132, 201209.

[8] Mohod, M. V. and Kadam, K. N. (2016). A comparative study on rigid and flexible pavement: a review. IOSR Journal of Mechanical and Civil Engineering (IOSR-JMCE), 13(3), 84-88.

[9] Shangguan, P. and Al-Qadi, I. L. (2014). Calibration of FDTD simulation of GPR signal for asphalt pavement compaction monitoring. IEEE Transactions on Geoscience and Remote Sensing, 53(3), 1538-1548.

[10] Belli, K., Rappaport, C. M., Zhan, H. and Wadia-Fascetti, S. (2009). Effectiveness of 2-D and 2.5-D FDTD ground-penetrating radar modeling for bridge-deck deterioration evaluated by 3-D FDTD. IEEE Transactions on Geoscience and Remote Sensing, 47(11), 3656-3663.

[11] Annan, A. P. (2003). Ground penetrating radar principles, procedures, and applications. Sensors and Software Inc. Mississauga, ON, Canada.

[12] Alani, A. M., Tosti, F., Ciampoli, L. B., Gagliardi, V. and Benedetto, A. (2020). An integrated investigative approach in health monitoring of masonry arch bridges using GPR and InSAR technologies. NDT and E International, 102288.

[13] Al-Qadi, I. L. and Lahouar, S. (2005). Measuring layer thicknesses with GPR-Theory to practice. Construction and building materials, 19(10), 763-772.

[14] Fa, W. (2013). Simulation for ground penetrating radar (GPR) study of the subsurface structure of the Moon. Journal of Applied Geophysics, 99, 98-108.

[15] Bai, H. and Sinfield, J. V. (2020). Improved background and clutter reduction for pipe detection under pavement using Ground Penetrating Radar (GPR). Journal of Applied Geophysics, $172,103918$.

[16] Smith, S. S. and Scuillion, T. (1993). Development of ground-penetrating radar equipment for detecting pavement condition for preventive maintenance. STIN, 95, 11904.

[17] Al-Qadi, I. L. (1992). Using microwave measurements to detect moisture in asphaltic concrete. Journal of testing and evaluation, 20(1), 43-50.

[18] Rmeili, E. and Scullion, T. (1997). Detecting stripping in asphalt concrete layers using ground penetrating radar. Paper No. 97-0508. Washington DC: Transportation Research Board.

[19] Asadi, P., Gindy, M., Alvarez, M. and Asadi, A. (2020). A computer vision based rebar detection chain for automatic processing of concrete bridge deck GPR data. Automation in Construction, 112, 103106.

[20] Damiata, B. N., Steinberg, J. M., Bolender, D. J., Zoëga, G., and Schoenfelder, J. W. (2017). Subsurface imaging a Viking-Age churchyard using GPR with TDR: Direct comparison to the archaeological record from an excavated site in northern Iceland. Journal of Archaeological Science: Reports, 12, 244-256. 
[21] Lachowicz, J. and Rucka, M. (2019). A novel heterogeneous model of concrete for numerical modelling of ground penetrating radar. Construction and Building Materials, 227, 116703.

[22] Ferrara, C., Barone, P. M., Salvati, L. and Pettinelli, E. (2014). Ground Penetrating Radar as remote sensing technique to investigate the root system architecture. Applied Ecology and Environmental Research, 12(3), 695-702.

[23] Maharaj, A. and Leyland, R. (2010). The dielectric constant as a means of assessing the properties of road construction materials. In Proceedings of the 29th southern African transport conference (SATC), South Africa, 487-498.

[24] Peplinski, N. R., Ulaby, F. T. and Dobson, M. C. (1995). Dielectric properties of soils in the 0.3-1.3-GHz range. IEEE transactions on Geoscience and Remote sensing, 33(3), 803-807.

[25] Yee, K. (1996). Numerical solution of initial boundary value problems involving Maxwell's equations in isotropic media. IEEE Transactions on Antennas and Propagation, 14(3), 302-307.

[26] Berenger, J. P. (1994). A perfectly matched layer for the absorption of electromagnetic waves. Journal of computational physics, 114(2), 1994, 185-200.

[27] Taflove, A. and Hagness, S. C. (2005). Computational electrodynamics: the finite-difference time-domain method. Artech house. 